\title{
A LÓGICA DE UM DICIONÁRIO REMISSIVO
}

José Marcelino Poersch*

SÍNTESE - A lexicografia constitui, na atualidade, uma área de estudos lingüísticos que, fundamentada na observação das necessidades dos usuários, mostra novas orientações no sentido de satisfazê-las. A idéia de elaborar um dicionário no qual as palavras se encontrem organizadas de acordo com seus múltiplos enlaces, tanto paradigmáticos quanto sintagmáticos, e ao qual o consulente, premido por problemas de esquecimento ou de desconhecimento lexical, recorra com o objetivo de encontrar a expressão exata de um conteúdo que queira vincular, além de constituir-se num projeto extremamente ousado, certamente preencherá uma lacuna e representará um significativo avanço no mundo lexicográfico.
ABSTRACT - Writer's sometimes face embarrassing situations when they do not know or when they forget the exact word to match a given situation. When the exact word is missing, the writer has to use analogies or circumlocutions that can interfere in the accuracy and intelligibility of the text. As the word is not present in the writer's memory, conventional dictionaries are helpless; we must develop a specific one where the words are organized according to their paradigmatic and syntagmatic relations and where the missing item, through continuous remissions, can be found. This dictionary will certaily supply an important gap and will represent an expressive progress in the lexicographical universe.

\section{1 - Heureka, o encontro da expressão através do conteúdo}

A seleção e a adequação vocabular constituem requisitos fundamentais de um bom texto. O escritor depara-se, não raras vezes, com situações embaraçosas de esquecimento ou de desconhecimento de palavras exatas para expressar determinados conteúdos. Os problemas de esquecimento relacionam-se com a memória: registro e recuperação; o desconhecimento explica-se pelo fato de o vocabulário armazenado na memória não corresponder à totalidade do léxico de uma língua e pelo fato de o vocabulário ativo ser sensivelmente inferior ao vocabulário passivo. $\mathrm{Na}$ falta de um termo exato, o escritor usualmente lança mão de circunlóquios. Estes, bem como o uso de palavras ambíguas e sinônimos mal selecionados, podem comprometer a precisão e a clareza textual. Considerando que os dicionários convencionais partem da palavra para fornecer seu conteúdo, a necessidade que o escritor tem de, partindo do conteúdo, encontrar sua expressão, neles não encontra a solução procurada. Baseado nas teorias semânticas da estrutura do signo verbal $\mathrm{e}$ das relações paradigmáticas e sintagmáticas interlexicais e também baseado nas teorias cognitivas do processamento e da recuperação lexical, e utilizando uma

Centro de Pesquisas Lingüisticas do Instituto de Letras e Artes - PUCRS 
metodologia específica, objetiva-se elaborar um dicionário remissivo que possibilite ao escritor, a partir de um conteúdo determinado e através de remissões sucessivas, encontrar a palavra que satisfaça a necessidade do texto. Para a consecução desse objetivo, será necessário o levantamento de todas as palavras relacionadas com cada uma das palavras-chave e 0 armazenamento dessas palavras num banco de dados especificamente elaborado para esse fim. Esse banco pode apresentar-se graficamente, em forma de dicionário, ou eletronicamente, acoplado a um editor de texto. A elaboração de um dicionário no qual o consulente encontra as palavras organizadas de acordo com seus múltiplos enlaces, além de ser um auxiliar eficaz para escritores prosaicos, para redatores e para tradutores, certamente preencherá uma importante lacuna e representará um significativo avanço no mundo lexicográfico.

\section{2 - As metas da investigação}

Nas inúmeras atividades humanas, constata-se que o primeiro concebido na mente (a intenção) será o último a ser atingido na ação. Na presente pesquisa, existe um objetivo claro a ser atingido - objetivo geral - e existem outros - intermediários ou operacionais - que servem de degraus para o atingimento daquele. Esses dois constituem os objetivos imediatos e serão alcançados pelas ações e procedimentos que esta investigação estabelece. Ainda há um outro grupo de objetivos - mediatos - que serão obtidos a longo prazo através de novas ações ou pela utilização dos produtos propiciados pela intenção primeira.

\subsection{Objetivos imediatos}

2.1.1. Objetivo geral. Motivado pelas desagradáveis influências que as limitações do desconhecimento lexical e que as deficiências da memória lexical acarretam aos produtores de texto em língua portuguesa, objetiva-se elaborar um dicionário às avessas, um dicionário que, partindo de um determinado conteúdo e utilizando remissões sucessivas, permita encontrar a expressão escrita adequada para o conteúdo a ser veiculado.

\subsubsection{Objetivos operacionais}

2.1.2.1 - Determinar as palavras-chave através de um estudo aprofundado da estrutura hierárquica vocabular, da freqüência de uso e da produtividade relacional de itens lexicais;

2.1.2.2 - Realizar um levantamento completo dos verbetes que se relacionam sintagmática ou paradigmaticamente com cada uma das palavras-chave;

2.1.2.3 - Elaborar um programa para registro dos dados produzidos pelo procedimento anterior;

2.1.2.4 - Efetuar o registro efetivo dos dados nesse banco.

2.1.2.5 - Realizar a impressão gráfica desses dados. 


\subsection{Objetivos mediatos}

2.2.1. Instrumentalizar o escritor com uma ferramenta adequada para executar sua obra com perfeição: munir os produtores de texto de um dispositivo rápido e eficiente que permita diminuir a influência negativa provocada, na redação textual, pelo esquecimento ou pelo desconhecimento lexical;

2.2.2. Prover os editores de texto de um dispositivo de acesso e consulta ao dicionário remissivo;

2.2.3. Fornecer uma contribuição válida e significativa aos estudos semânticos, tanto da lexicologia - relação interlexical - quanto da lexicografia - dicionário remissivo.

\section{3-A anatomia do problema}

\section{1 - Constatação de fatos}

Um jornalista, ao tomar conhecimento de um sinistro acontecido nos subúrbios da cidade e ao acompanhar as diversas diligências executadas pelos bombeiros para debelar o incêndio, trata de remeter, de imediato, material para a central jornalística. Em determinada altura do relato, ele está a escrever o seguinte: "Da torre de vigia foi localizado o incêndio. Imediatamente os bombeiros tomaram posição no carro e rumaram ao local começando a luta contra as chamas. Precisaram reabastecer o carro. Para sua felicidade, encontraram na redondeza um(a) (aquela tomada ou torneira a que se adapta a mangueira para reabastecer o carro dos bombeiros). Qual não foi sua decepção ao constatar que o(a) sativado(a)". estava de-

No momento da escritura da crônica, o jornalista sabia exatamente a que ele estava se referindo não se lembrando, no entanto, da palavra hidrante, denominação dada àquele objeto hidráulico.

A falta de uma denominação ou de um item lexical no momento de seu uso constitui um sério obstáculo ao processo da comunicação, principalmente se se tratar de uma produção escrita. $\mathrm{O}$ falante ou escritor sabe claramente $\mathrm{o}$ que quer dizer/escrever; a prova disso é que ele consegue utilizar um rodeio de palavras que induz o ouvinte/leitor a fornecer o termo exato a ser incluído no texto.

Entre outros exemplos, podem ser citados os seguintes:

- Qual é a expressão grega (interjeição) usada quando se acha a solução de um problema? Em português, diz-se "achei".

- Heureka

- Como se denominam as colunetas de madeira, concreto ou metal que sustentam um peitoril em sacadas ou um corrimão em escadarias?

- Balaústre

- Qual é a palavra utilizada para denominar o cano ou tubo através do qual escapa (escorre) a água em excesso de um reservatório?

- Ladräo

- Como se chama a frutinha redonda e preta, de gosto agridoce, que cresce rente aos galhos e que amadurece no início da primavera? 
- Que sinônimo pode substituir a palavra "apagar" as chamas?

- Qual é o antônimo de "útil"?

- Que advérbio geralmente acompanha o adjetivo "claro"?

- Prejudicial

- Meridianamente

- Qual é o verbo que se usa para "enxergar, mal e mal, não nitidamente, ao longe"?

- Vislumbrar

- Que palavra substitui a lacuna da frase seguinte: "Ele deve todos os itens do formulário antes de devolvê-lo?

- Preencher

- Devemos a comida antes de engoli-la.

- Mastigar

É deveras corriqueiro, na comunicação lingüística, em formas e quantidades variadas, o falante/escritor deparar-se com situações embaraçosas nas quais a disponibilidade da palavra exata para o momento certo nem sempre existe. Sabe-se, com clareza, o que se quer dizer; a maneira correta de expressar esse conteúdo é que se torna problemática. A expressão popular "tenho a palavia na ponta da língua" alude a esse fato. Na verdade o que se tem é o conteúdo; a expressão é que não é lembrada.

\section{2 - Explicação do fato}

Existem duas vertentes que podem explicar a falta de um termo que expresse determinado conteúdo (conceito). De um lado, não se sabe a palavra; ela nunca foi aprendida. Trata-se de um problema de conhecimento. $\mathrm{O}$ desconhecimento lexical explica-se pelo fato de o vocabulário armazenado na mente humana - vocabulário disponível - não corresponder à totalidade do léxico existente na língua e pelo fato de o vocabulário ativo ser sensivelmente inferior ao vocabulário passivo (Zechmeister, 1993). O vocabulário registrado na mente de cada utente constitui uma parcela do léxico total da língua; esta é um somatório dos léxicos parciais de cada falante. Nenhum dicionário, por mais completo que seja, reúne o léxico total da língua.

Por outro lado, trata-se de um problema de esquecimento e relaciona-se com a memória: registro e recuperação lexical; a palavra que foi alguma vez aprendida, por motivos diversos, não é recuperada no momento preciso. Um detalhamento mais aprofundado dessa explicação deriva da estrutura diádica do signo verbal: signo lingüístico e signo semiológico. O signo lingüístico é um signo mental, criado na mente dos utentes da língua a partir da união de um conceito e de uma representação sonora. A cada signo lingüístico corresponde um signo físico, de relação triádica - o signo semiológico; este responde, na comunicação, pela transmissão, pelo contato entre os parceiros. Trata-se de "uma coisa que, além da espécie ingerida pelos sentidos, faz vir ao pensamento, por si mesma, qualquer outra coisa", segundo Santo Agostinho (apud Barthes, 1975). Enquanto o primeiro traduz o 
segundo, isto é, faz corresponder uma seqüência sonora a um referente, o segundo, por ser produzido e captado pelos sentidos, é responsável pelo contato estabelecido entre os parceiros da comunicaçã̃o. O problema do desconhecimento ou do esquecimento reside no fato de que, em certas circunstâncias, um determinado conteúdo não desperta a sua correspondente representação sonora; esta, por sua vez, representa mentalmente o signo semiológico, isto é, a sua expressão sonora ou gráfica. Esquecer, nesse sentido, é não encontrar o laço que une a expressão ao conteúdo.

O problema do desconhecimento está relacionado com o fato de determinados conteúdos, para determinados falantes, jamais terem sido ligados a expressões correspondentes. Em ambos os casos, trata-se de um problema de memória, esta conceituada como a capacidade de registrar, armazenar e recuperar informação - lexical, no presente caso (Luria, 1979).

A moderna teoria do conexionismo (Young and Concar, 1992) lança novas luzes sobre o funcionamento da memória. Os dados da experiência são percebidos através de canais diversos (sentidos) e são registrados, na mente, em pontos distintos, de acordo com esses canais aferentes. Os registros são feitos nos neurônios; estes, por sua vez, são todos interconectados através das sinapses e, assim, formam verdadeiras redes neuroniais. Quando dois ou mais registros forem simultâneos, correntes elétricas reforçam essas sinapses. Esse reforço possibilita a que um determinado conteúdo - ou experiência - ative, mais ou menos instantaneamente, outros conteúdos que com eles estiverem conectados.

As diversas palavras aprendidas, de acordo com a situação em que forem aprendidas, estabelecem conexões com outras palavras. Conexões específicas são estabelecidas entre conceitos e representações sonoras ou gráficas. No caso de uma palavra ser aprendida, isto é, ligar um conteúdo a uma expressão sonora, as sinapses entre esse conteúdo e a respectiva expressão são reforçados, de maneira que, ao ouvirmos uma palavra, ligamos a essa seqüência sonora - na mente constitui uma representação sonora - o significado correspondente e, vice-versa, quando algum conceito é despertado, na mente, automaticamente sua expressão correspondente é ativada.

Causas diversas, como estados psíquicos adversos, senilidade, situações doentias, cansaço, estresse podem debilitar essas sinapses ou, até, anulá-las momentaneamente, a ponto de, em determinadas circunstâncias, tornar-se difícil ou mesmo impossivel recordar a palavra para determinado conteúdo ou o significado de determinada palavra.

\section{3 - Conseqüências do fato}

A comunicação lingüística processa-se através de textos. Sabe-se que a exigência fundamental de um texto é a coesão e a coerência. No entanto, também é evidente que a precisão vocabular constitui um atributo importante para que ela apresente clareza e precisão. $\mathrm{O}$ ato de bem escrever, numa sociedade letrada como a nossa, constitui uma habilidade que se transforma numa arma poderosa para disseminar as idéias, para promover a cultura e o desenvolvimento e para pregar a paz. 
A não-recordação de um item lexical, no exato momento em que sua presença é necessária, como no caso do jornalista referido anteriormente, além de criar angústia de parte do usuário da língua, dificulta o fluxo do raciocínio e chega, às vezes, a comprometer a comunicação. As conseqüências negativas desse problema atingem qualquer produtor de comunicação, tanto os utentes do texto falado, quanto - e principalmente - os utentes de textos escritos. Assim, o jornalista citado, se estivesse narrando o fato em vez de escrevê-lo, o uso de circunlóquio ou de paráfrase bastaria; o interlocutor compreenderia e, talvez, inseriria, na mensagem, o termo exato - hidrante.

Normalmente, em casos de desconhecimento ou de esquecimento, tem sido utilizado o circunlóquio - a torneira onde os bombeiros ligam a mangueira para abastecer os carros pipas com água - ou sinônimos - "apagar" em vez de "debelar". Esse expediente, no entanto, compromete a precisão e, às vezes, a clareza do texto. Outra solução seria o recurso ao interlocutor ou a uma terceira pessoa. Essas estratégias, embora consigam geralmente resolver o problema no nível da expressão oral, certamente não podem ser recomendados na produção de textos escritos onde a interação escritor/leitor não se realiza no próprio ato da escrita como sói acontecer no uso de uma comunicação oral informal.

Também aos produtores de linguagem oral formal - no caso de conferencistas, oradores, professores, repentistas - não é facultado parar para pensar porque seu discurso exige uma fruição constảnte; assim, eles devem encontrar rapidamente ou um sinônimo ou elaborar um circunlóquio. Também não podem recorrer aos parceiros visto que esse tipo de comunicação não permite o uso desse recurso. Os escritores, por outro lado, dispõem de mais tempo para pensar, para organizar o seu pensamento, para vestir de expressão o conteúdo a. veicular; essa disponibilidade também nem sempre resolve o impasse.

Em sintese, as conseqüências que o desconhecimento ou o esquecimento acarretam aos produtores de texto consistem num terrivel mal estar e uma generalizada insatisfação. A tensão produzida pela falta de termos exatos, nesse momento, até chega a gerar dificuldades para a própria ordenação das idéias e, quem sabe, até problemas na transposição dessas idéias em expressões lingüísticas.

Uma solução para os escritores seria o recurso ao dicionário, estratégia a qual eles normalmente recorrem quando encontram problemas de significado, de grafia, de repetição lexical. Essa procura é possível porque os dicionários convencionais partem de uma determinada expressão (vocábulo) para encontrar seu significado, para conferir sua grafia, saber sua etimologia, seu regime, seus antônimos, sinônimos ou palavras afins.

Praticamente todos os produtores de discurso, oral ou escrito, são afetados negativamente pelas conseqüências de seu esquecimento ou desconhecimento lexical. Na produção oral citam-se, principalmente, os conferencistas, os professores, os pregadores, os locutores e os discursadores. Na produção escrita, relacionam-se os escritores - em prosa e em verso - os jornalistas, os relatores técnicos, os correspondentes e os tradutores, entre outros. 


\section{4 - Tentativas de solução}

O problema acima descrito reside, então, basicamente, em não ter, no momento preciso, um termo adequado para expressar determinado conteúdo. $O$ problema em análise teve apontadas possibilidades de soluções emergenciais. $\mathrm{O}$ uso de circunlóquios e de sinônimos normalmente atenta contra a adequação e a precisão vocabular. O recurso a outras pessoas, além de tornar-se incômodo, muitas vezes fica impraticável. Outra solução apontada seria o uso do dicionário; o recurso a dicionários convencionais também fica descartado pelo fato de estes normalmente partirem de uma determinada palavra da qual fornecem o significado.

A lexicografia, ciência que se ocupa da elaboração de dicionários, glossários e vocabulários, é, na atualidade, uma área de estudos que tenta se desenvolver e ganhar maior evidência dentro da lingüística aplicada. Ao longo das décadas passadas, pouco tem sido feito para melhorar as obras lexicográficas com a utilização efetiva dos conhecimentos que a ciência lingüística nos coloca à disposição. Ao contrário, observa-se que muitos dicionários não passam de repetições, com pequenas variações, de obras já ultrapassadas, tanto em conteúdo quanto em apresentação.

O levantamento das necessidades dos usuários em relação aos dicionários pode apontar para novos rumos dentro da área lexicográfica. Sabe-se que os motivos que levam um indivíduo a utilizar um dicionário geral de uma língua variam bastante: há consultas, muitas vezes, em busca de significados de palavras desconhecidas; outras, motivadas por dúvidas de ortografia ou de regime de verbos ou nomes; ainda outras há para a obtenção de sinônimos ou antônimos. Nesses diversos casos, o consulente parte de uma palavra que lhe está mentalmente disponível no momento da consulta, isto é, tem acesso ao item de seu interesse. Dito isso de outra maneira, a' palavra é o ponto de partida para a procura. Nessa situação, o dicionário convencional pode desempenhar seu papel com propriedade.

Entretanto, há que considerar a possibilidade, não rara, de o usuário necessitar de uma palavra que ele sabe ser adequada para um determinado texto, mas cuja forma ele nunca soube ou não consegue lembrar. Nesse caso, o item procurado não se encontra à disposição na mente do indivíduo; este se esforça para recuperar da memória uma informação que lhe escapa naquele momento. A consulta a um dicionário convencional, em tal situação, não lhe fornece uma resposta aceitável, uma vez que é necessário que o consulente já tenha tido, no mínimo, acesso à forma física da palavra buscada. Como não é esse o caso, o indivíduo tenta recordarse, intuitiva e automaticamente de palavras que se relacionem com aquela que não lhe ocorre. Nesses casos, podem ser úteis dicionários etimológicos, dicionários analógicos, dicionários de palavias afins, dicionários denominados "Thesaurus", dicionários enciclopédicos e outros assemelhados. Entretanto, em muitas oportunidades, tal procedimento resulta infrutífero.

A dificuldade de recuperar da memória palavras que se adequam perfeitamente a um certo contexto, ou seja, que denominam determinados objetos, caracteristicas, ações e relações com necessária exatidão, tem sido, amiúde, mencionado em estudos da área cognitiva. Pesquisas tem atribuído tal dificuldade a problemas de reconhecimento ou a problemas de recordação; a memória humana é capaz de ar- 
mazenar uma grande quantidade de itens lexicais, dos quais o vocabulário passivo é superior ao vocabulário ativo (Zeichmeister et al., 1993). Até hoje, no entanto, poucas tentativas tem sido levadas a cabo para eliminar os obstáculos à recordação de palavras, na prática. Dessa realidade decorre a necessidade de serem empreendidos projetos audazes e capazes de oferecer uma solução, em nivel prático, para o problema.

Os lingüístas, ao abordarem o assunto, verificam que no signo verbal, as palavras se relacionam de diversas maneiras, quer no nível paradigmático quer no nível sintagmático (Saussure, 1971). Essas relações podem ser do tipo morfológico - aspectos da expressão e do conteúdo -, do tipo analógico - as diversas palavras compartilham traços semânticos comuns -, do tipo esquemático - as palavras se agrupam, se conectam no mundo experiencial -, e do tipo sintático - as palavras coocorrerem em mesmos ambientes textuais.

Por outro lado, a ciência da cognição estuda os aspectos de aquisição, de armazenamento e de recuperação dos itens lexicais. Em parte, todo item lexical está aliado ao plano do conteúdo e ao plano da expressão (Hjelmslev, 1975). Como o conteúdo e a expressão nem sempre são adquiridos concomitantemente e como 0 signo lingüístico é formado pela união de um significado e um significante e como os itens lexicais estão interconectados na memória, a sua recuperação pode apresentar problemas: no momento da comunicação, o significado está presente, ao passo que o significante respectivo está ausente.

Essas idéias trazidas pela lingüística e pelas ciências cognitivas oportunizam a elaboração de um dicionário baseado nessas múltiplas relações interlexicais onde uma palavra estaria vinculada com inúmeras outras. Dessa maneira, ao termos um determinado conteúdo, a sua expressão seria encontrada através de remissões sucessivas de palavras relacionadas com aquele conteúdo.

É nessa perspectiva que se vislumbra uma solução prática e eficaz para as dificuldades trazidas, pelo desconhecimento e pelo esquecimento lexical, para a produção de textos.

\section{5 - Razões para a elaboração de um dicionário remissivo}

Marobin (apud Heckler et al., 1984), na introdução ao Dicionário Morfológico da Língua Portuguesa, afirma que "a palavra humana é o melhor instrumento de expressão e de comunicação do ser humano, e quanto melhor o conhecimento e o domínio das palavras, melhor será sua expressão e comunicação".

Sendo que a seleção e a adequação vocabular constituem exigências de um bom texto, este deve eliminar, ao máximo, o uso de palavras ambiguas, sinônimos imperfeitos e circunlóquios que atentam contra sua clareza e sua precisão. Assim, - Heureka constituir-se-á em um auxiliar eficaz para utentes do código escrito, mormente para escritores prosaicos, redatores e tradutores.

Os consumidores do produto deste projeto - o dicionário remissivo - impresso e/ou eletrônico, caracterizam-se pelo fato de serem produtores de textos escritos e que, devido à necessidade de apresentarem o máximo de clareza e de precisão na expressão do conteúdo a veicular, precisam de um instrumento pronto e eficaz 
para dirimir - ou, ao menos, diminuir - as influências negativas que a falta de conhecimento lexical ou seu esquecimento podem acarretar a esses textos.

Entre os usuários do código escrito que poderão usufruir os benefícios oriundos da utilização desse dicionário, relacionam-se os seguintes:

- escritores em prosa e verso (poetas, romancistas, cronistas, teatrólogos, novelistas e jornalistas em geral);

- produtores tanto de textos de informação e de formação quanto de livros didáticos;

- diretores e secretários (em seus relatórios, em suas atas, em suas correspondências e em seus memoranda);

- redatores técnicos de relatórios de pesquisa (teses e dissertações), de comunicações para congressos e de artigos para revistas;

- tradutores de textos em língua estrangeira para o português;

- usuários do português escrito para falantes do português como segunda língua ou como língua estrangeira.

A fundamental importância dos dicionários no mundo atual tem levado muitos lexicógrafos a buscar melhores meios de organizá-los bem como torná-los cada vez mais práticos e úteis. Desde meados do século XIX foram feitas várias tentativas no sentido de abandonar o método mecânico de agrupamento de palavras por ordem alfabética, buscando uma classificação segundo os conceitos que eles exprimem. Um marco precursor, de valiosa importância nesse sentido, foi o surgimento do Roget's International Thesaurus elaborado pelo médico inglês P. M. Roget (Roget, 1952). Além dessa, outras obras importantes surgiram no sentido de aprimorar os dicionários e torná-los mais completos e úteis.

Entre os diversos dicionários atualmente existentes, além dos meramente convencionais - que partem do vocábulo para o significado - há os que contribuem para auxiliar os produtores de textos em situações de desconhecimento ou de esquecimento de itens lexicais. Os dicionários morfológicos trazem os termos oriundos de raízes ou de radicais comuns. Os dicionários analógicos trazem os termos que compartilham traços semânticos. Os dicionários de termos afins apresentam palavras evocadas esquematicamente a partir de outras. Os "thesaurus" procuram reunir os dados dos dois últimos sem, contudo, trazer o seu significado. Ultimamente apareceu, em inglês, um dicionário de colocações (Benson et al., 1986).

Segundo uma revisão bastante ampla das obras lexicográficas, não se encontrou nenhum, principalmente em língua portuguesa, que se mostrasse suficientemente útil para trazer uma solução satisfatória a todos os problemas originados por lapsos de memória e por fatos de desconhecimento. Isso realça a importância do presente projeto: elaborar um dicionário que, através de remissões sucessivas, leve o usuário da língua a encontrar a palavra exata para um determinado conteúdo.

Nesse sentido, o projeto "Heureka, o dicionário remissivo" vem preencher uma lacuna no conjunto das obras lexicográficas em lingua portuguesa pois não há registro de outra obra que tenha atingido satisfatoriamente os objetivos que este projeto se propõe alcançar. As poucas obras, em Português, que, por suas características, poderiam constituir uma tentativa para sanar o problema oriundo pelas falhas na seleção de itens lexicais, mostram-se por demais restritas na formulação e insuficientes no conteúdo. 
Com uma nova concepção de obra lexicográfica, o presente projeto tem por objetivo elaborar um dicionário capaz de apresentar os diversos tipos de relações entre palavras nos campos da etimologia, da morfologia, da semântica lexical e da sintaxe lexical. Porém, a tarefa mais inovadora no projeto, a concepção mais criativa, será a organização das palavras na obra. Aliando os dados oriundos da revisão de trabalhos de conceituados pesquisadores a uma observação atenta dos procedimentos seguidos por usuários de dicionários na recuperação de palavras, chega-se à proposta de organizar.os itens lexicais em grupos encabeçados por palavras-chave. Assim, a necessidade de contextualização da palavra - amplamente relatada em pesquisas de cunho lingüístico e cognitivo - estará sendo suprida, já que o usuário só tem como ponto de partida o contexto em que a palavra ocorre. Com tal tipo de organização, o usuário ganha tempo, pois a consulta torna-se bem mais prática e bem mais objetiva.

São grandes as vantagens advindas da execução de um projeto da envergadurạ do dicionário remissivo. Antes de mais nada, ressalte-se a enorme contribuição ao campo dos estudos lingüísticos, pois constitui empreendimento pioneiro na área. Esse projeto, sem dúvida, com a elaboração desse tipo de dicionário, promove a ampliação dos horizontes da lexicografia no Brasil.

Além das evidentes vantagens científicas, o projeto traz beneficios em termos práticos, pois propõe-se suprir uma lacuna que, até agora, nenhuma obra lexicográfica conseguiu suprir. Os habituais usuários de dicionários, como escritores, conferencistas, estudantes e professores universitários, jornalistas e, enfim, as pessoas que lidam freqüentemente com a palavra em sua rotina profissional de pesquisa e docência, terão a sua disposição uma obra capaz de resolver suas dúvidas, com grande economia de tempo, sempre que a recordação de um termo se fizer necessária.

Embora a obra que o projeto pretende elaborar possa vir a ser publicada pelos meios tradicionais de impressão gráfica, o projeto pretende igualmente torná-la disponivel para uso eletrônico em computador, acoplada a editores de texto. Com isso, suas perspectivas de utilização nos meios educacionais e profissionais serão ampliadas, sem deixar de mencionar o fato de que a obra poderia ser atualizada receber novas versões - sem passar pelos demorados procedimentos exigidos por uma obra impressa.

Como vantagens adicionais, a execução do projeto, ao exigir um amplo levantamento dos vocábulos da língua, estará promovendo o desenvolvimento de sistemas computacionais de armazenamento, de conferência e de cotejo de dados lingüísticos. Esses dados, por sua vez, assim como o conhecimento científico que são capazes de gerar, poderão ser utilizados como subsídios tanto para estudos dentro do próprio Centro de Pesquisas Lingüísticas da PUCRS quanto para investigações em nível estadual e nacional.

\section{6 - Conclusão: o "rationale" de uma hipótese de trabalho}

Uma observação atenta feita em atos de produção lingüística mostra que, vezes sem conta, falantes/escritores depararam-se com situações embaraçosas: não têm à disposição, no momento exato de seu uso, uma palavra que expresse com 
clareza um conceito a inserir na mensagem. Afirmou-se, repetidas vezes, que 0 costumeiro uso, nestes casos, de circunlóquios, de paráfrases, de sinônimos, normalmente atentam contra a clareza e a precisão do discurso.

A anatomia do problema, além de localizar sua causa imediata no desconhecimento ou no esquecimento lexical - ambos relacionam-se com a mente - ainda aponta para conjecturas de soluções válidas, prontas e eficazes.

No nivel lexicológico, a estrutura lexical mostra que os diversos itens lexicais estão inter-relacionados de diversas maneiras, quer em seus aspectos sintagmáticos, quer em seus aspectos paradigmáticos.

No nível semiológico, o estudo da palavra está ligado ao signo verbal, composto de um constituinte físico - signo semiológico - e de um signo mental - signo lingüístico. $\mathrm{Na}$ aquisição do signo, o conceito e a expressão nem sempre são apreendidos simultaneamente.

No nível cognitivo são oferecidas explicações sobre a maneira como os itens lexicais são processados na mente, como é feito seu armazenamento e sua recuperação. $\mathrm{O}$ armazenamento. se processa em forma de redes semânticas onde os itens se interligam já que eles se fixam em neurônios distintos ligados entre si pelas sinapses. Quanto mais consistentes forem essas sinapses - por ocorrências simultâneas de dois itens - tanto mais forte será a vinculação e mais fácil e instantânea será sua evocação.

O ponto crucial do problema reside exatamente na ligação estabelecida entre um conceito e uma representação sonora. O problema está localizado no ponto em que, para um determinado conceito, não fica automaticamente disponível a representação sonora correspondente.

Considerando os aspectos das relações que as palavras têm entre si na língua e as redes de conexões com que as palavras se armazenam na memória e, ainda, considerando a estrutura diádica do signo lingǘstico, talvez a existência de um dicionário remissivo, elaborado com base nesses múltiplos enlaces lexicais, possibilite ao utente da lingua, em casos de esquecimento ou de desconhecimento, através de remissões sucessivas, encontrar a expressão correta para um conteúdo determinado.

\section{Referências Bibliográficas}

BARTHES, Roland. Elementos de Semiologia. São Paulo: Cultrix, 1975.

BENSON, Morton; BENSON, Evelyn and ILSON, Robert. The BBI Combinatory Dictionary of English.

Amsterdam/Philadelphia: John Benjamin's Publishing Company, 1986.

HECKLER, Evaldo; BACK, Sebald; MASSING, Egon. Dicionário Morfológico da Língua Portuguesa. São

Leopoldo: UNISSINOS, 1984.

HJELMSLEV, Louis. Prolegômenos a uma teoria da linguagem. São Paulo: Perspectiva, 1975.

LURTA, A. R. Pensamento e linguagem: as últimas conferências de Luria. Porto Alegre: Artes Médicas, 1987.

ROGET, Peter Mark. Roget's International Thesaurus. New York: Thomas Y. Crowell Company, 1852.

SAUSSURE, Ferdinand de. Curso de lingüistica geral (3a ed.). São Paulo: Cultrix, 1971.

YOUNG, Stephen \& CONCAR, David. "These cells were made for learning". New Scientist, $\mathrm{n}^{\mathrm{e}} 21$ (26-30),

21 November 1992. 